\title{
The Role of Figurative Language Use in the Representation of Tourism Services
}

\author{
By Elmira Djafarova*
}

\begin{abstract}
The majority of tourism research explores the images represented visually, as the visual plays a vital part in the production and performance of tourism services. Less attention is paid to the text in this context, although it also has a strong visual element expressed in words. The language, which represents tourism, has a central connection with tourists' attitudes that deserves to be included in the research. Tourism is a service industry and its products are not easily tested. Customers are dependent on the marketing activities for constructing the images of these services. This article explores the use of figurative language, specifically metaphors and puns and its contribution to the communication of tourism images. Relevance Theory, a pragmatic approach helps to understand how puns and metaphors are interpreted. Figures of speech enhance representation of tourism services visually and help to attract the attention to the presented services. According to Relevance Theory, to ensure successful use of figures of speech, more anchoring is required in the text. This will help consumers shape tourism images. The article attempts to provide preliminary outcomes, which would further assist the research in similar areas of language use.
\end{abstract}

Keywords: tourism, figurative language, marketing communication, Relevance Theory, pragmatics.

\section{Introduction}

Limited research is undertaken to understand the way the language is used in tourism (Djafarova and Andersen, 2008; Dann, 1996). The majority of tourism research explores the images represented visually (Urry, 1990; Gonzalez and Bello, 2002). Little attention is paid to verbal expression, while it also has an important visual element (Williamson, 1978). Dann (1996) argues that through media, the language of tourism attempts to persuade people to become tourists and successively controls their attitudes and behaviour. Tourists contribute to this language through the communication of their experiences (Dann, 2012). Tourism consists of a range of services and the key feature of service experience is the high involvement of the customer in the communication process (Grönroos, 2011; Holmqvist, 2011). Language in tourism advertising communicates certain ideas and values to potential tourists (Gonzalez and Bello, 2002).

There has been a little discussion between researchers who primarily study linguistics, and those who mainly focus on tourism services (Dann, 1996). In creating and presenting such relationships, this study aims to make contribution to the emerging debates in linguistics and tourism disciplines. The aim is to

\footnotetext{
${ }^{*}$ Principal Lecturer, UK.
} 
place linguistics (more specifically pragmatics, a branch of linguistics) at the centre of studying tourism language. Linguistics is also a product of social relations and it is necessary to explore and understand how its meanings have been constructed and used across tourism experiences (Chomsky, 1986).

This conceptual study is arranged into the theoretical framework with attention to tourism and its consumers. It then explores the use of language in tourism marketing, with more detailed account of figures of speech. Later parts of the paper introduce and incorporate pragmatics into the interpretation of figurative language. Pragmatics, a study of meaning and signs within the context, provides an insightful interpretation of tourism images. This research offers contribution to knowledge in theoretical concepts related to the way linguistic devices are employed to depict tourism services. The study shows how figures of speech can create the identities of tourists, destinations, tourist attractions, and other tourism services. Concluding remarks highlight challenges of this type of language use in tourism services description and present possible implications.

\section{Tourism Services and Potential Consumers}

Tourism is an important element of modern life and modern society (Shaw and Williams, 2002; Mihelj, 2010). Modern society is characterized by increase of mobility in search for new experiences through tourism activities (Bastida and Huan, 2014). Consumers have more choices to spend their leisure time and activities to undertake during the holiday (Timothy and Wall, 2001; Yeoman et al., 2006; Djafarova and Andersen, 2008). New tourists' interests shift towards in-depth experiences and affect overall demand factors (Mihelj, 2010). As a result, tourism marketers present new services to increasingly demanding customers, to ensure the success of their business (Cohen, 2004). Travel marketers face the challenge of making a variety of tourist activities fully available (Dewar et al., 2007). As the activities vary, marketers in turn need to be more sophisticated and creative in their choice of techniques and tools to influence consumers' opinions.

Saarinen (2004) argues that tourism and tourists have become increasingly distinctive features of contemporary societies and global market, and the economic significance of tourism. Tourism has become an important element in a social process of change in which human systems, values and communities are being integrated in a move towards global social and economic networks (Jaworski and Pritchard, 2005).

\section{Language Use in Marketing Tourism}

Gonzalez and Bello (2002, p. 53) argue, that "tourism is a service with its own unique nature, thanks to its chief characteristics". Those characteristics of tourism make the marketing side of it important and challenging for tourism management. Tourism, being about a set of different experiences and not about a single product, makes it an important factor in the approach undertaken by 
the marketers (Dewar et al., 2007). They face challenge of creating and forming tourism images. Marketing research in relation to language influence on consumer is extensive (Van Vaerenbergh and Holmqvist, 2013).

Krippendorf (1987) argues that marketing techniques of tourism are the same as those used in any type of services, but because they deal with desires and dreams, people and cultures, a greater responsibility is placed on the marketers. Manuel et al. (1996) says that in order to sell a product/service, tourism marketers present an idealized image of tourism. Myths of tourism differ from myths in literature and films, as tourism eventually bring tourists to the real world (Dann, 2002). Tourists are still obsessed with their dream wishes, but they are open to experience the images they have received through marketing communication channels. Tourism creates an unreal surrounding within which physical activity takes place (Dann, 2002). Imaginary and reality of tourism balance one another.

Tourists first of all choose a destination and only then make a decision about accommodation and other services (Lickorish and Jenkins, 1997; Ortega and Rodriguez, 2007). Therefore, the impact the image of the destination has on the customer is considered significant in the consumer's decision-making process (Batista and Huan, 2014). The tourism destination image-creating process is mostly studied to explain tourist behaviour (Gallarza et al., 2002, Baloglu, 2000). The importance of the tourist destination's image is well acknowledged, since it affects the tourist's subjective perception and attitudes in choosing a destination (du Rand and Heath, 2006; Beerli and Martin, 2004, Ekinci et al., 2014). Images are important as perceptions and ideas stimulate customers to act more than reality itself (Gallarsa et al., 2002; Ritchie and Crouch, 2000). Every destination offers different types of services and products. Creative language enhances the attraction of tourists to the image of the destination (Djafarova and Andersen, 2008). This decision depends on personal motivations and destination image perceptions by the tourist (Beerli and Martin, 2004). Travellers' images of tourism destinations are to a great extent influenced by the sources of information they are exposed to. Being a key element of the decision-making process, the aim is to visualize the characteristics of the destination image (as a type of tourism service) and to familiarise tourists with it (Gallarza et al., 2002, Baloglu, 2000).

Understanding the concept of image is central to the understanding of tourism. An image develops a vision through which a person perceives his/her environment. This image development depends on person's beliefs, perceptions and attitudes (Pink, 2001). Consumers form various images, which relate to tourism services formed on the basis of promotion, previous experiences and other aspects (Morgan and Pritchard, 1998). Tourist image influences the decision making of the consumer (Urry, 1990). Morgan and Pritchard (1998) point out a wide range of functions of images in tourism, which varies from enhancement of positive perceptions of the product to communication of messages about certain places. Language is used to form the images in consumers' minds. Figurative language is one of these vehicles within the texts (Phillips and McQuarrie, 2004). 


\section{Figurative Language}

Figures of speech as figurative devices of language are extensively researched in the context of language and communication studies (McQuarrie and Mick, 1996; 1999; McQuarrie and Phillips, 2005; Mothersbaugh et al., 2002). Phillips and McQuarrie (2004) conclude that consumers are more favourable to the use of figures of speech, as it helps them visualize intangible items. Figures of speech are one of the few linguistic elements of marketing activities that require academic interest (McGuire, 2000; McQuarrie and Mick, 1996; 1999; Mothersbaugh et al., 2002; Toncar and Munch, 2001). Rhetorical practice (practice of persuasion through language use) is known as a way to influence the opinions of addressees through language (Corbett, 1990). Figures of speech have a great impact on communication and they aim to enhance the techniques of this communication (McQuarrie and Mick, 1996).

For the purposes of this research, figurative language is defined as various language techniques, which balance normal language use in any type of communication. By normal language it is meant all the components of language directly expressing the intended meaning. Normal meaning is denotative meaning, or the dictionary definition of the utterance (Barthes, 1964). It is a meaning, which does not require any extra processing effort from the addressee to understand it.

According to Phillips and McQuarrie (2002), marketers choose to reduce the verbal explanation offered to consumers. Therefore, they place the intended meaning at risk of being misunderstood. Figures of speech have been found to increase elaboration process (interpretation time) because the consumer has to think and process the meaning of the figure of speech in the message (McQuarrie and Mick, 1999; Mothersbaugh et al., 2002). Furthermore, increased elaboration can benefit the mnemonic effect of the message. In addition, the consumers' pleasure in recovering a figure can lead to increased attention (McQuarrie and Mick, 1996) and a positive attitude toward the services described. The argument put forward in this research is whether the playfulness of figures of speech can satisfy the tastes of consumers or risk linguistic misunderstanding. Metaphors and puns are among the most commonly employed figures of speech in marketing communications channels and explored further in this article (Phillips and McQuarrie, 2002).

\section{Metaphors Use in Tourism Language}

The metaphor is the basis of figurative language, commonly used not only in literature, but also in day-to-day communication and other types of texts. The function of the metaphor is not just to provide an enjoyable picture in the mind of the receiver. Metaphors encourage a re-conceptualisation of what is already given. They can be mental models for sense making, aiding the communication (de Chernatony and Dall'Olmo Riley, 1997; Davies and Chun, 2003). Elgin (1993) argues that every person has his/her own way to interpret and understand the meaning of metaphors. This process may cause some 
confusion what precisely has been expressed by the metaphor (Elgin, 1993). However, metaphors may address people who share common values, attitudes and behaviour towards a particular phenomenon (Phillips and McQuarrie, 2002).

Tourism services are characterized by the use of metaphor, and it possibly derives from the special characteristics of the tourism subject (Djafarova, 2008). It is hard to define tourism in terms of one particular product or service, and this specific characteristic of tourism makes it more attractive and appropriate to play with its interpretation in marketing related language (Dann, 2012). Creating artful and figurative meanings, metaphors enhance the imagery in tourism (Paivio and Clark, 1986; Ang and Lim, 2006).

A study conducted by Ang and Lim (2006) divides the products into symbolic and utilitarian. According to this subdivision, tourism products are of a symbolic type. Ang and Lim (2006: 42) argue that "symbolic products are consumed for sensory gratifications and affective purposes or for fun and enjoyment". Utilitarian products possess more tangible attributes and a rational appeal. The above study concludes that symbolic products appear to be more exciting and emotional but are not associated with sincerity as much as are utilitarian products, and metaphors lessen the perception of sincerity for symbolic products (Djafarova and Andersen, 2010). Being imaginative and exciting, the tourism benefits from the qualities of metaphors but there are some disadvantages that must not be overlooked. Current trends have an effect on the market and on the behaviour of the potential consumers (Mihelj, 2010). Changes in the preferred types of tourist services consequently lead to change in tourist expectations and needs. Morgan and Pritchard (2000) argue that current trends in the industry put more pressure on communication of tourism services today.

When metaphor is used in the text, it automatically directs the customer to look at the product from a different point of view (Palmer and Lundberg, 1995). It opens new ways of perceiving the object. The metaphors, which are used to portray tourism objects, help potential customers to interpret meaning and structuring the realities. The form in which the metaphor is created may vary. The notion of an island paradise can be quickly put across by signifying images of beautiful beaches and pleasant weather (Krippendorf, 1987). Dann (2002) emphasises that of those images, perhaps the most frequently employed is that of sun, along with the images of dreams, heaven and escape.

The metaphor is used mainly to cope with the unfamiliarity of a destination for the traveller (Dann, 1992). When promoting long-haul destinations, which are unfamiliar to tourists, some promotional texts try to reduce the factor of strangeness and include some familiar features, which draw the associations in tourists' minds (Blasko and Connine, 1993). For example, in the phrase "Antalya. This place is pure sun and sand territory", a comparison is made between the unfamiliar destination and pleasant climate conditions. By drawing the parallels between the common qualities of two objects (Antalya and sun and sand territory) the reader is able to form the image of the destination, which offers sun and sand featured tourism activities 
(Kress, 1989; Lakoff and Johnson, 1980). Given that the metaphor is used to reduce the unfamiliarity of features of the presented object, it should rationally follow that its usage tends to increase in direct relationship to the strangeness of the destination being pictured. As the cultural difference increases so does the use of metaphor (Dann, 1996). The reader reacts to the text, which is relevant to her/him, to the text where information about the place or service looks familiar. Thus, one particular role of the metaphor is to reduce the effect of unfamiliarity.

The metaphor makes a reader consider new associations by drawing links between the source domain object and target domain object of the metaphor (Young, 2000). Consequently, the reader re-conceptualizes his/her old ideas and opinions about the tourism service described. The following example illustrates this function of metaphor. In the sentence "Thailand is a paradise", the reader maps together common attributes between the tourist destination Thailand and a paradise. The reader is forced to draw links and make associations between these two objects. Some of the qualities of Thailand could be missed out if the text simply addresses Thailand as a tourist destination. Common qualities such as beauty and comfort might be derived from the interpretation of this metaphor. It makes the reader think beyond and draws more comprehensive characteristics of the destination (Kittay, 1987). Metaphor allow the readers to look at the described image from a different point of view, which they would not expect to see in a different context, but as the aim is to attract attention of the customer and sell the product, positive features are expected to be emphasized in this context (Paivio and Clarke, 1986). Metaphors offer a pleasant and amusing experience to the readers, making the latter think about the intended meanings in each instance (Scott, 1994). Marketers understand this role and use it to attract more customers.

\section{Use of Puns in Tourism Representation}

Another common figure of speech is known as pun or play on words. The pun is a figurative device used in everyday speech, often in poetry and as it is found within the academic literature (Leigh, 1994). It usually has a humorous function in the text. Puns are considered in the literature in relation to the function and role of humour in marketing activities. It is one of the linguistic devices most frequently exploited to attract consumers' attention (Tanaka, 1994).

A quantitative study by McCullough and Taylor (1993) concludes that the tourism and travel category is the one with the highest average humour ratings. McCullough and Taylor (1993) suggest that the high humour level in the tourism industry is appealing, given to the expressive elements built in the leisure area. Puns may have represented a low-key, less risky form of humour especially fitting to business audiences.

The additional processing effort demanded is rewarded for the increased power of the message conveyed or the increased memorability of the text. An opinion, which the audience might discount as being of little credibility, is 
strengthened and possibly remembered because of the extra processing effort involved (Tanaka, 1994). Extra contextual effects are based on the audience's pleasure and satisfaction at having solved the pun: these may affect the audience's attitude to the portrayed service. Thus, a reliance on the consumer's knowledge of the context to resolve a figure of speech increases (Phillips and McQarrie, 2002). In the example "Eiffel in love in Paris" (Pun of the Day, 1996), one is expected to possess some knowledge about Paris to understand this pun. No additional words are provided to anchor this interpretation; the audience's interest in Paris is assumed to be sufficient to enable the comprehension.

One of the points to clarify is what considers as being a greater or lesser processing effort. Thus, it is necessary to identify certain factors that influence the processing effort when interpreting puns in the text (Tanaka, 1994). The processing effort tends to be less complex and therefore a potential consumer can derive the meaning that is suitable for them. One way to measure the input of processing the effort required is through the level of abstraction expressed through the pun. The functions of the pun vary and it affects the processing effort (Djafarova, 2008). Another way to measure the processing effort is the ability of the reader to understand and recover the intended meanings of the pun. This point emphasises the links between the interpretation of puns and the inferential abilities of the readers. Inferential abilities depend on a series of factors. These factors depend on the background of the reader, his/her knowledge of the described product, consumer competence, his/her attitudes, needs and opinions of the world in general (Tanaka, 1994).

\section{Figures of Speech in Tourism Advertising}

Figures of speech contribute to this representation of tourism, but each has its own way to communicate as interpretation might differ from one individual to another. Creating words, many ways of interpretation must be considered and each has to be representative of tourism images but not misleading and confusing. Behind all the ambiguity the real meanings and ideas should be incorporated.

Metaphors are convenient devices to express the meaning of something intangible (Kendall and Kendall, 1993; Ortony, 1993). However, metaphors appear to be complex, expressing abstract meanings and lack of substantial information about the product. Hence, the intended meaning might be lost behind the magnitude of metaphors. Advertisement "Discover holiday heaven to the east of Eden. Crylla Valley Cottages. A holiday experience... beyond self-catering", "holiday heaven" refers to a quality of the offered holiday. However, nothing explicitly has been mentioned about this quality. "Heaven" can be interpreted very broadly, and everyone would extract his/her own meaning under this notion. It is convenient to use figures of speech for marketers to lessen their responsibility for the interpretation of meanings, but readers face a challenge of processing the ambiguity in these devices 
(McQuarrie and Mick, 1996). Hence, complicated ambiguous figures of speech do not do justice to the communication process.

The following message 'Sri Lanka isn't known as the 'Pearl of the Orient' for nothing' is another example of metaphorical use. The associations with the qualities of pear come to reader's mind when processing the right relationships between 'pearl' and 'Sri Lanka'.

Nevertheless, the issues of misinterpretation might occur when metaphorical patterns do not explicitly express the intended visual images of tourism. Ang and Lim (2006) argue that products expressed by metaphors are less honest than non-metaphorical representations. Ang and Lim (2006) say that metaphors reduce the sincerity of the symbolic products to which they refer tourism service too.

Phillips and McQuarrie (2002) argue that communication of the metaphors is more successful owing to the anchoring (follow-up explanation of metaphor). The degree of this anchoring would depend on the type of metaphors used. In the case of abstract (concept-based) metaphors more anchoring is expected to make the right assumptions of the meanings (Djafarova and Andersen, 2008). Metaphors might not always be successful as they can be misinterpreted, misunderstood or have no actual informative visual account if not enough of information is provided, particularly in relation to abstract notions, which are hard to visualise.

Tourism being an intangible product and tourists becoming more sophisticated can cause some misinterpretations in metaphorical language. The abstract (concept-based) images derived from metaphors do not fully contribute to the understanding of tourism services if not enough of follow up explanation is applied. Object-based metaphors can be more beneficial in addressing sophisticated consumers. They are easier to interpret as they express certain objects, which do not require extra processing effort from readers. Concept-based metaphors can only be adequately interpreted and visualise tourism products if the advertiser produces enough of contextual effects and explains the intended meaning of the communicated metaphor (Djafarova and Andersen, 2010). Current trends dictate the representation of the visual in tourism communication, which is required to follow the needs of potential tourists. Object-based metaphors are easier to interpret as they have greater ability of being visualised, as they carry a small amount of the processing effort (Djafarova, 2008). However, no matter how much processing effort is required to understand any metaphor, its interpretation depends on the initial assumptions the reader holds about the described object. In its turn these assumptions depend on more personal processing abilities of the reader. These abilities are dictated by the knowledge the reader pursue about the object and general abilities to recover the information. Therefore, the main interpretation of the metaphor is determined by the reader's background and general knowledge (Tanaka, 1994; Djafarova, 2008). This interpretation also depends on the degrees of abstraction, which metaphors convey. 
It is becoming more difficult to attract potential consumers just with the use of words, especially in the case where the tourism product is intangible and heterogeneous. Competition from various types of information technology might threaten print communication in future (Arens et al., 2008). Therefore, today words should comprise different creative devices to attract the attention of modern tourists with the higher expectations. Frechtling (1987) says that marketers should be careful not to give too many promises as they will have to respond to complaints if they do. Although the amount of complaints has reduced, tourism is still among the industries with the most complaints.

The real meanings are not always uncovered behind the wittiness of puns, which means that in times no informative meaning is involved. For example, in the advertisement "Seafari. Get away from the usual holiday stampede - Go "AUREOL" to West Africa. Be different this year! Elder Dempster Lines", play of words takes place in using "seafari" which resonates with "safari" holidays to Africa. The processing work of puns is similar with the interpretation of metaphors, as both devices express certain ambiguity. However, puns involve higher level of ambiguity due to their playful nature, thus the interpretation process may require more processing effort. This extra processing effort makes the message stay longer in the memory of the reader, thus attracting more attention to the object (Phillips and McQarrie, 2002). Hence, it could be argued that pun is effective in creating interest and attracting attention to the product, while metaphor is more successful in building awareness of a new product.

Without a reasonable amount of information consumers can be left unsatisfied by misunderstanding the described image, as no actual information is provided in the text. According to Ang and Lim (2006), symbolic products become even more ambiguous when figurative devices are involved. The characteristics of tourism services underpin its high-risk nature and the dependence on the external factors.

\section{Pragmatics and Relevance Theory: Metaphors and Puns}

This research adopts pragmatics to analyse and understand the use of metaphors and puns. Pragmatics studies the utterance interpretation within the context (Carston, 2002). The rules of pragmatics underpin the theory, outlined by Sperber and Wilson (1981), known as Theory of Relevance. This theory explains that the reader interprets the meaning of communication most relevant to them within certain context (Sperber and Wilson, 1981). Relevance Theory is based on Grice's maxims (1981; 1989, see Figure 1). Grice (1981) uses the term 'the cooperative principle' when referring to the way in which people try to make the communication process successful. The cooperative principle suggests that one's contribution should be as it is required by the situation (Grice, 1975). He indicates that in usual setting of communication addressee and addresser share a cooperative principle. Speakers shape their utterances to be understood by addressees. Grice (1975) argues that in order to understand what other people are trying to communicate, they usually follow specific 
rules. These rules are introduced as four maxims by Grice (1975), presented in the Figure 1 below.

Figure 1. Four Maxims of Grice (Adapted from Grice, 1975)

1. The Maxim of Quality

Try to make your statement sound true and have an evidence for this true statement.

2. The Maxim of Quantity

Give the right amount of information, i.e. make your contribution as informative as is required.

3. The Maxim of Relation

Be relevant. Make sure that the information is of relevance to the addressee and the intended meaning is easily derived.

4. The Maxim of Manner

Be perspicuous, i.e. avoid ambiguity.

Relevance Theory helps to understand why some meanings, but not others, are recovered in the process of interpretation of puns and metaphors. It confronts issues such as, how to disambiguate ambiguous meanings or how to interpret utterances whose content is superficially irrelevant to their context (Stern, 1990).

According to Relevance Theory, communication of metaphor is consistent with the principles of relevance as the time spent on processing the metaphor is substituted by the reward the reader gets for the derivation of the right meaning. Placing an abstract notion in the form of metaphor, communicators try to make the meanings as relevant to the context and the reader as possible. The accompanying element, referred to as anchoring (extra wording which follows the key message and helps to understand the meaning), which helps the interpretation of the figures of speech, can be used in the texts to ease the interpretation (Tanaka, 1994)

The process of the metaphor and pun interpretation depends on the degree of figurative involvement in the text. It means that the processing effort required for the interpretation of the figure of speech is influenced by the level of difference between the target and source subjects of the figure speech (Wilson and Sperber, 1988; Leigh, 1994). Anchoring helps interpretation processes of the intended meanings of the figurative trope. Inferential and processing abilities of the reader are important elements in the process of the metaphor and pun derivation. Metaphors are consistent with the principles of the Relevance Theory due to its contextual effects and relevance to the context (Djafarova, 2008). According to Relevance Theory, readers are rewarded by the extra processing effort spent to interpret metaphors/puns (Tanaka, 1994). However, growing competence and awareness of modern tourists raise the expectations from marketing material where they require seeing more informative side of the service. Abstract metaphors are entertaining but do not let consumers draw the adequate image of the tourism services. 
Similar conclusions are drawn in relation to interpretation of puns. According to Relevance Theory (Wilson and Sperber, 1988; Tanaka, 1994), readers are rewarded for the extra processing effort by the pleasurable experience they receive for solving the pun. The main function of the pun, according to this theory is sustaining the memory for a longer time. However, Relevance Theory is only applicable if there are enough contextual effects in the text and if the reader has enough inferential abilities to extract the right meaning. The pun plays with the meaning and intrigues the readers, but it can be debated whether the intended meaning is always interpreted successfully or whether readers just derive the meaning they feel confident about the most.

Communicator would estimate the intellectual level of his/her market target in order to make the pun understood and appropriate to its receiver. Only when he/she is completely able to interpret the message and can derive the optimal relevance, solving puns rewards the reader and the attention of the reader is sustained for a longer time. It requires readers to use their contextual knowledge of tourism or concepts related to the travel and tourism activities such as culture and geography. Puns may imply more than can legally be expressed explicitly in words. Therefore, puns encourage consumers to draw conclusions about the product and the marketing message that go beyond what is stated in the text (Messaris, 1997).

The overall change in expected consumer competency is considerable, as marketers have moved from assuming that even a simple figure of speech needs to be explained, assuming that no explanation is required for such devices today, where it is assumed that no anchoring is needed (Phillips and McQuarrie, 2002).

\section{Conclusion}

Recommendations on how to achieve successful communication through the use of puns and metaphors are embedded in this section. An extra anchoring is required if the figure of speech takes place, in order to be able to recover the ambiguity. Targeting a particular audience, the marketers still cannot adequately estimate the personal and intellectual abilities of the customers. Thus, some anchoring contributes to the interpretation process of puns/metaphors. One could argue that figure of speech would lose its identity if the correct answers were overtly stated. However, it would also depend on whether the pun/metaphor carries some essential information or whether it is there just to catch attention. In the examples obtained for this research, information is an important part of puns and metaphors, particularly when dealing with services, where the marketing image often is the first to strike prospective consumers. Play on words in its own right cannot achieve the informative objective of communication. The processing effort of puns is high but consistent with the Relevance Theory if anchoring is provided. Puns and metaphors with its functions of attracting attention are suitable for reinforcing the knowledge to already familiar products. 
The aim of this research is to produce theoretical links between the disciplines and to explore the significance of these relations. This study contributes to the theoretical knowledge within the areas of tourism language and service marketing. Some researchers have adapted a pragmatic approach but they did not center on specific figurative devices. They draw their conclusions from the implications within the language use. The pragmatic approach, being an analytical tool in this research, combines and balances different disciplines to contribute to knowledge in these fields.

This study highlights the importance of figurative language in communication of services and explores opportunities of this type of language use in tourism sector. Ambiguity expressed through figurative language in services can be equal to the ambiguity/misunderstanding caused by the use of different language, a language that is unfamiliar to the consumer. Previous research shows that consumers favor the use of native language in services to minimize the risk of misunderstanding (Van Vaerenbergh and Holmqvist, 2013). It could also indicate the use of extra anchoring when using ambiguous figures of speech in the representation of services. More clarity is needed in communication when dealing with high involvement services.

Tourism is a social phenomenon and its participants use language to make tourism. Relevance Theory, a pragmatic approach, explains the interpretation process of metaphors and puns and suggests more anchoring would assist the comprehension and visualization of the figures of speech describing services.

Further research can explore wider variety of figures of speech and also investigate any cultural differences in the comprehension of this type of language in service marketing. Empirical study would be able to test the current research against consumer responses to the discussed figures of speech. This paper explored tourism area as a case of service and further work can be conducted to investigate other types of services.

\section{References}

Ang, S. H., and Lim, E.A. C. 2006. The Influence of Metaphors and Product Type on Brand Personality Perceptions and Attitudes. Journal of Advertising. 35, 2, 39-53.

Arens, W. F., Weigold, M. F., and Arens, C. 2008. Contemporary Advertising. $11^{\text {th }}$ Edn. London, McGraw-Hill Higher Education.

Baloglu, S. 2000. A path-analytical model of visitation intention involving information sources, socio-psychological motivations and destination images. In Woodside, A. G., Crouch, G. I., Mazanec, J. A., Oppermann, M., and Sakai, M. Y. Consumer psychology of tourism, hospitality and leisure. USA, CABI Publishing, 63-90.

Barthes, R. 1964. Rhetoric of the Image. The Responsibility of Forms: Critical Essays on Music, Art and Representation. Richard Howard, Berkeley, California.

Bastida, U., and Huan, T. C. 2014. Performance evaluation of tourism websites' information quality of four global destination brands: Beijing, Hong Kong, Shanghai, and Taipei. Journal of Business Research. 67, 2, 167-170.

Beerli, A., and Martin, J. F. 2004. Factors influencing destination image. Annals of Tourism Research. 31, 3, 657-681. 
Blasko, D. G., and Connine, C. M. 1993. Effects of familiarity and aptness on metaphor processing. Journal of Experimental Psychology: Learning, Memory and Cognition. 19, 2, 295-308.

Carston, R. 2002. Thoughts and utterances. The pragmatics of explicit communication. Oxford, Blackwell.

Chomsky, N. 1986. Knowledge of language, Its nature, origin, and use. New York, Praeger.

Cohen, E. 1993. The Study of Touristic Images of Native People: Mitigating the Stereotype of a Stereotype, 36-69 in Pearce, D., and Butler, R. Tourism Research: Critiques and Challenges. London, Routledge and Kegan Paul.

Dann, G. M. S. 1996. The Language of Tourism: A Sociolinguistics Perspective. UK, $\mathrm{CAB}$ International.

Dann, G. M. S. 2002. The tourist as a metaphor of the social world. UK, CABI Publishing.

Dann, G. M. S. 2002. Theoretical Issues for Tourism's Future Development, Identifying the Agenda. In Pearce, D.G., and Butler, R.W. Contemporary Issues in Tourism Development, London, Routledge.

Dann, G. 2012. Remodelling a changing language of tourism: from monologue to dialogue and trialogue. Revista de Turismo y Patrimonio Cultural. 10, 4, 59-70.

Davies, G., and Chun, R. 2003. The use of metaphor in the exploration of the brand concept. Journal of Marketing Management. 19, 1/2, 45-71.

de Chernatony, L., and Dall'Olmo Riley, F. 1997. The chasm between managers' and consumers' views of brands: the experts' perspectives. Journal of Strategic Marketing. 5, 2, 89-104.

Dewar, K., Li, W. M. and Davis, C. H. 2007. Photographic Images, Culture, and Perception in Tourism Advertising: A Q Methodology Study of Canadian and Chinese University Students. Journal of Travel and Tourism Marketing, 22, 2, 35-44.

Djafarova, E. 2008. Why Do Advertisers Use Puns? A Linguistic Perspective. Journal of Advertising Research. 48, 2, 267-275.

Djafarova, E., and Andersen, H-C. 2008. Contribution of Figurative Devices to Representation of Tourism Images. Journal of Vacation Marketing. 14, 4, 291 303.

Djafarova, E., and Andersen, H-C. 2010. Visual Images of Metaphors in Tourism Advertising. In Burns, P., Palmer, C. Lester, A., and Bibbings, L. Tourism and Visual Culture: Methods and Cases, 2. CABI Publishing, 36-42.

Du Rand, G. E., and Heath, E. 2006. Towards a Framework for Food Tourism as an Element of Destination Marketing. Current Issues in Tourism. 9, 3, 206-234.

Ekinci, Y., Sirakaya-Turk, E., and Preciado, S. 2013. Symbolic Consumption of Tourism Destination Brands. Journal of Business Research. 66, 6, 711-718.

Elgin, S. 1993. Genderspeak. Men, Women and the Gentle Art of Verbal Self-Defence. New York, Wiley.

Frechtling, D. C. 1987. Five issues in tourism marketing in the 1990s. Tourism Management. June, 177-178.

Gallarza, M. G., Saura I.G., and Garcia, H. C. 2002. Destination image: Towards a Conceptual Framework. Annals of Tourism Research. 29, 1, 56-78.

Gonzalez, A. M., and Bello, L. 2002. The construct "lifestyle" in market segmentation. The behaviour of tourist of tourist consumers. European Journal of Marketing. 36, 1/2, 51-85.

Grice, H. P. 1975. Logic and conversation. In P. Cole, and J.L. Morgan, Syntax and Semantics, 3, Speech Acts, New York, Academic Press, 41-58. 
Grice, H. P. 1981. Presupposition and conversational implicature. In Cole, P., and Morgan, J. L. Radical pragmatics. New York, Academic Press, 183-198.

Grice, H. P. 1989. Studies in the Way of Words. Cambridge, Mass., Harvard University Press.

Grönroos, C. 2011. Value of co-creation in service logic: A critical analysis. Marketing Theory. 11, 3, 279-301.

Holmqvist, J. 2011. Consumer language preferences in service encounters: a crosscultural perspective. Managing Service Quality. 21, 2, 178-191.

Jaworski, A., and Pritchard, A. 2005. Discourse, Communication and Tourism. Clevedon, Channel View Publications.

Kendall, J. E., and Kendall, K. E. 1993. Metaphors and boundaries: Living beyond the systems machine. MIS Quarterly. 17, 147-171.

Kress, G. 1989. Linguistic Processes in Sociocultural Practice. Oxford, Oxford University Press.

Krippendorf, J. 1987, The Holiday Makers, Understanding the Impact of Leisure and Travel. Oxford, Heinemann.

Lakoff, G., and Johnson, M. 1980. Metaphors We Live By. Chicago, University of Chicago Press.

Leigh, J. H. 1994. The use of figures of speech in print ad headlines. Journal of Advertising. 23, 2, 18-33.

Leiper, N. 2004. Tourism Management. Australia, Pearson.

Lickorish, L. J., and Jenkins, C. L. 1997. An Introduction to Tourism. Oxford, Nutterworth-Heinemann.

McCullough, L. S., and Taylor, R. K. 1993. Humor in American, British, and German Ads. Industrial Marketing Management. 22, 1, 17-28.

McGuire, W. J. 2000. Standing on the Shoulders of Ancients: Consumer Research, Persuasion, and Figurative Language. Journal of Consumer Research. 27, June, 109-114.

McQuarrie, E. F., and Mick, D. G. 1996. Figures of Rhetoric in Advertising Language. Journal of Consumer Research. 22, 4, 424-438.

McQuarrie, E. F., and Mick, D. G. 1999. Visual Rhetoric in Advertising: TextInterpretative, Experimental and Reader-Response Analyses. Journal of Consumer Research. 26, 1, 37-54.

McQuarrie, E. F., and Phillips, B. J. 2005, Indirect Persuasion in advertising. How consumers process metaphors presented in pictures and words. Journal of Advertising. 34, 2, 7-20.

Messaris, P. 1997. Visual persuasion: the role of images in advertising.

Thousand Oaks, London; Sage.

Mihelj, V. 2010. New tourists products for new tourists' expectations. Tourism and Hospitality Management. May, 1075.

Morgan, N. J., and Pritchard, A. 1998. Tourism, Promotion and Power. Chichester, Wiley.

Morgan, N. J., and Pritchard, A. 2000. Advertising in Tourism and Leisure. Oxford, Butterworth Heinemann.

Mothersbaugh, D. L., Huhmann, B. A., and Franke, G. R. 2002. Combinatory and Separative Effects of Rhetorical Figures on Consumers' Effort and Focus in Ad Processing. Journal of Consumer Research. 28, March, 589-602.

Ortega, E., and Rodriguez, B. 2007. Information at tourism destinations. Importance and cross-cultural differences between international and domestic tourists. Journal of Business Research. 60, 2, 146-152.

Ortony, A. 1993. Metaphor and Thought. Cambridge University Press. 
Paivio, A., and Clark, J. A. 1986. The Role of Topic and Vehicle Imagery in Metaphor Comprehension. Communication and Cognition. 19, 3/4, 367-387.

Palmer, I., and Lundberg, C. C. 1995. Metaphors of Hospitality Organizations, An Exploratory Study. Cornell Hotel and Restaurant Administration Quarterly. 36, 3, 80-85.

Phillips, B. J., and McQuarrie, E. F. 2004. Beyond Visual Metaphor: A New Typology of Visual Rhetoric in Advertising. Marketing Theory. 4, 113-136.

Phillips, B. J., and McQuarrie, E. F. 2002. The Development, Change, and Transformation of Rhetorical Style in Magazine Advertisements 1954-1999. Journal of Advertising. Winter, 31, 4, 1-13.

Pink, S. 2001. Doing Ethnography: Images, Media and Representation in Research. London, Sage.

Pun of the Day 1996. Available at: http://www.punoftheday.com/cgi-bin/disppuns.pl? ord $=M \&$ cat $=0 \&$ sub $=0 \&$ page $=1$ (Accessed 10 August 2016).

Ritchie, J. R. B., and Crouch, G. I. 2000. The competitive destination: A sustainability Perspective. Tourism Management. 21, 1-7.

Saarinen, J. 2004. Destinations in change' the transformation process of tourist destinations. Tourist Studies. 4, 2, 161-179.

Shaw, G., and Williams, A. 2002. Critical Issues in Tourism: A Geographical Perspective. Oxford, Blackwell.

Stern, B. 1990. Beauty and Joy in Metaphorical Advertising: The Poetic Dimension. Advances in Consumer Research. 17, 71-78.

Tanaka, K. 1994. Advertising Language, a Pragmatic Approach to Advertisements in Britain and Japan. London and New York, Routledge.

Timothy, D. J., and Wall, G. 2001. Tourism and Political Boundaries. London, Routledge.

Toncar, M., and Munch, J. 2001. Consumer Response to Tropes in Print Advertising. Journal of Advertising. 30, 1, 55-65.

Urry, J. 1990. The Tourist Gaze: Leisure and Travel in Contemporary Societies. London, Sage.

Van Vaerenbergh, Y., and Holmqvist, J. 2013. Speak my language if you want my money. European Journal of Marketing. 47, 8, 1276-1292.

Williamson, J. 1978. Decoding Advertisements: Ideology and Meaning in Advertising. London, Marion Boyars.

Wilson, D., and Sperber, D. 1988. Mood and the analysis of non-declarative sentences. In Dancy, J., Moravcsik, J., and Taylor, C. Language and Value. Stanford, Calif., Stanford University Press, 229-324.

Yeoman, I., Munro, C., and McMahon-Beattie, U. 2006. Tomorrow's: World, consumer and tourist., Journal of Vacation Marketing. 12, 2, 174-190.

Young, B. M. 2000. The child's understanding of promotional communication. International Journal of Advertising and Marketing to Children. 2, 3, 191-203. 
